\title{
Evaluating VIIRS Ocean Color Products for West Coast and Hawaiian Waters
}

\author{
Curtiss O. Davis ${ }^{\mathrm{a}}$, Nicholas Tufillaro ${ }^{\mathrm{a}}$, Jasmine Nahorniak ${ }^{\mathrm{a}}$, Burton Jones ${ }^{\mathrm{b}, \mathrm{d}}$ and Robert Arnone ${ }^{\mathrm{c}}$ \\ ${ }^{\mathrm{a} C o l l e g e ~ o f ~ E a r t h, ~ O c e a n ~ a n d ~ A t m o s p h e r i c ~ S c i e n c e s, ~ O r e g o n ~ S t a t e ~ U n i v e r s i t y, ~} 104$ CEOAS Admin. \\ Bldg., Corvallis, OR, 97331 USA \\ ${ }^{\mathrm{b}}$ Department of Biological Sciences, University of Southern California, Los Angeles, CA, 90089, \\ USA \\ 'Department of Marine Science, University of Southern Mississippi, Stennis Space Center, MS, \\ 39529, USA \\ dKing Abdullah University of Science and Technology, Thuwal 23955-6900, Kingdom of Saudi \\ Arabia
}

\begin{abstract}
Automated match ups allow us to maintain and improve the ocean color products of current satellite instruments MODIS, and since February 2012 the Visible Infrared Imaging Radiometer Suite (VIIRS). As part of the VIIRS mission Ocean Calibration and Validation Team, we have created a web-based automated match up tool that provides access to searchable fields for date, site, and products, and creates matchups between satellites (MODIS, VIIRS), and insitu measurements (HyperPRO and SeaPRISM). The goal is to evaluate the standard VIIRS ocean color products produced by the IDPS and available through NOAA's CLASS data system. Comparisons are made with MODIS data for the same location, and VIIRS data processed using the NRL Automated Processing System (APS) used to produce operational products for the Navy. Results are shown for the first year of VIIRS data matching the satellite data with the data from Platform Eureka SeaPRISM off L. A. Harbor in the Southern California Bight, and HyperPRO data from Station ALOHA near Hawaii.
\end{abstract}

Keywords: Ocean Color, VIIRS, Satellite Chlorophyll, NPP, Vicarious Calibration

\section{INTRODUCTION}

As part of the VIIRS mission Ocean Calibration and Validation Team, we have created a web-based automated match up tool that provides access to searchable fields for date, site, and products, and creates matchups between satellites (MODIS, VIIRS), and in-situ measurements. The goal is to evaluate the standard VIIRS ocean color products produced by the IDPS and available through NOAA's CLASS data system. Comparisons are made with MODIS data [1] for the same location, VIIRS data processed using the NRL-APS and in situ data from Platform Eureka (CA) SeaPRISM and HyperPRO profiles collected at Station Aloha near Hawaii. The VIIRS sensor on the Suomi National Polar-Orbiting Partnership (NPP) satellite has five spectral channels centered at 410, 443, 486, 551 and $671 \mathrm{~nm}$ that are used to characterize spectral ocean color with additional channels for atmospheric correction [2]. Current ocean color sensors in space used for monitoring the biochemical properties of ocean water including MODIS Aqua and Terra are near the end of their lifetimes. NPP VIIRS can provide continuity of these data products if sufficient sensor characterization and calibration are performed, including assessing the stability and consistency of ocean products. This effort includes continual validation of the VIIRS ocean color products in a wide variety of ocean conditions and assessing the accuracy of calibration and ocean color processing. The retrieval of ocean color spectrometry, i.e., normalized water leaving radiance $(\mathrm{nLw}(\lambda))$ requires that sensor calibration is tightly connected to the accurate removal of atmospheric radiance, surface glint and stray light. These sources of noise must be accurately removed from the top of the atmosphere radiances $(\operatorname{Lt}(\lambda))$ measured by the sensor [3,4]. These procedures have been applied to the present MODIS and other satellites and accurate products have been retrieved. The JPSS calibration and validation team has developed an infrastructure to evaluate VIIRS Ocean Environmental Data Records (EDRs): routinely $\mathrm{nLw}(\lambda)$ and chlorophyll are evaluated against existing satellites and in situ data measurements. Ocean color products are based on $\mathrm{nLw}(\lambda)$ from

Ocean Sensing and Monitoring V, edited by Weilin W. Hou, Robert A. Arnone, Proc. of SPIE Vol. 8724, 87240J · @ 2013 SPIE · CCC code: 0277-786X/13/\$18 · doi: 10.1117/12.2016177 
which specific products of chlorophyll, backscattering coefficients, absorption coefficients, and diffuse attenuation coefficients are computed. Therefore the accurate radiometric retrieval of the $n \operatorname{Lw}(\lambda)$ is considered essential for the production of any ocean color product.

Continuity of the ocean color products between ocean color satellites is required for climate studies, as well as to enhance the operational products used in ecological monitoring and forecasting, such as accurately monitoring ocean water quality and determining changes along our coastlines. These operational needs address community services such as the detection of harmful algal blooms, fishery hypoxia and ocean contaminants. All of these operational needs depend on the electro-optical system performance of the remote sensor, as well as the integration of products and validation in ecological forecast models. The utility of having multiple sources (looks per day) of ocean color products enhances our ability to retrieve cloud free conditions and monitor diurnal changes in water quality. In addition, intersatellite product comparisons are essential for data continuity into the future.

Since its launch on November 28, 2011, the VIIRS sensor has been actively characterized using an on-board calibrator and moon imaging to determine look up tables (LUTs) for sensor calibration used to produce Sensor Data Records (SDRs) and Environmental Data Record (EDR) products. Initially the calibration was changing rapidly, however since mid February 2012 the degradation has been well characterized and accurate calibration of the data is available since that time. The ocean color EDR products have been generated in combination with LUTs to examine the impact that the evolving LUTs have on EDR ocean color products. Ocean color products are most sensitive to sensor LUTs, since a significant amount of the signal ( $\sim 90 \%$ of the Lt) is from the atmosphere and must be removed during atmospheric correction. We use the ocean color products of $\operatorname{nLw}(\lambda)$ as a monitor to test the calibration accuracy of the sensor and the impact of changes in the LUT.

The Southern California Bight is a region of the North American West Coast bordered by Point Conception in the north to Ensenada Mexico to the south. The region is characterized by a subarctic offshore current flowing south, and a subtropical near shore current flowing north. The waters provide a rich biological transition zone. At its center lays the Los Angles Harbor. A snap shot of the region is shown in Figure 1. The region also includes Catalina and the Channel Islands. Chlorophyll levels vary seasonally, with levels reaching $5 \mathrm{mg} / \mathrm{m} 3$ or higher during spring blooms. There are several long term regional data records available, such as those from the California Cooperative Fisheries Investigations (CalCOFI) which show typical mean chlorophyll-a ranges from $0.1 \mathrm{mg} / \mathrm{m}^{3}$ to $2 \mathrm{mg} / \mathrm{m}^{3}$ which varies both seasonally and spatially [5].

Working closely with the Stennis Space Center Remote Sensing Group (NRL-SSC, USM, SDSU, QNA), and the Cooperative Remote Sensing Science and Technology Center (CREST) at the City College of New York (CCNY), we have developed an ocean color product validator for the US West Coast. Here we describe the validator and show results for the Southern California Bight and Station Aloha, north of Hawaii. The validator has three main goals. First, to help with the initial calibration of the recently launched VIIRS ocean color imager, second to assist with on-going calibration efforts with VIIRS and MODIS, and third, as a tool for researchers to quickly access and evaluate data from these sensors both for scientific studies and operational uses for government agencies such as NOAA or state environmental quality programs.

\section{DATA SOURCES AND METHODS}

For Monitoring VIIRS data and algorithm stability we provide near-real time match up of data from the Platform Eureka SeaPRISM with MODIS, MERIS, HICO and VIIRS data. This includes the automated selection of the satellite data for that site, production of products to match the AERONET data, and statistical analysis of the in situ and satellite data.

At the current time OSU is receiving near real-time data from:

MODIS data from NASA OBPG archived at OSU,

MERIS FR data from ESA down linked by CSA archived at OSU (through April 8, 2012),

VIIRS SDRs and Ocean EDRs from VOCCO NOAA CLASS (Ocean Channels SVM 01-07). 
Additionally, we are currently receiving and archiving VIIRS L3 APS processed data for West Coast Golden Regions from Bob Arnone's group at NRL [6], SeaPRISM data from Platform Eureka in the Los Angeles Harbor and collecting HyperPRO data at Station ALOHA as part of the Hawaiian Ocean Time Series (HOT).

\section{Platform Eureka, California}

In collaboration with Burt Jones at USC, the SeaPRISM site at Platform Eureka was installed in the Los Angeles Harbor and was initially operational April 2011. SeaPRISMs are part of the AERONET network of automated instruments designed to make automated measurements of aerosols around the world. The SeaPRISM instrument has been modified to also view the ocean surface and measure ocean color remote sensing reflectance as well as the aerosol measurements [7]. Data is currently flowing to NASA AERONET as well as NRL-SSC and OSU for matchups. Some power, communications, setup and cabling issues limited the initial data collections; however, data has been collected routinely since June 2012. Platform Eureka data is available at:

http://aeronet.gsfc.nasa.gov/cgi-bin/type_one_station_seaprism_new?site=USC_SEAPRISM\&nachal=2\&level=2\&place_code=10

The location, the installed instrument and example data from Platform Eureka are shown in Figure 1.
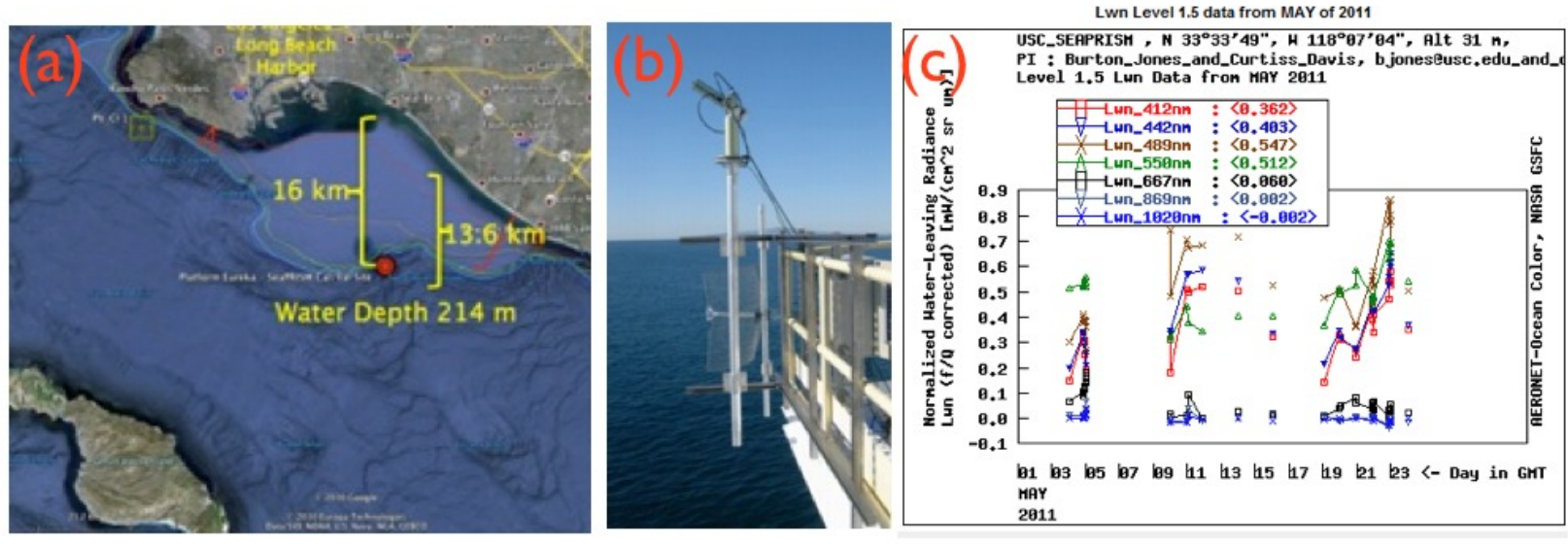

Fig. 1. Platform Eureka SeaPRISM installation in Los Angeles Harbor. (a) Location, (b) Photo of SeaPRISM, (c) Data display from NASA AERONET site for May 2011.

\section{Hawaii Ocean Time Series (HOT) Data}

To validate satellite data products such as VIIRS we have been collecting profiles of downwelling irradiance (Ed) and upwelling radiance (Lu) using a Satlantic HyperPRO at Station ALOHA north of Hawaii (Figure 2). These measurements are made routinely as part of the monthly Hawaiian Ocean Time Series (HOT) project [7], and are also collected during Hawaiian cruises led by the Center for Microbial Oceanography: Research and Education (C-MORE) [8]. HyperPRO data are collected as close as possible in time to satellite overflights.

The HyperPRO is a free-falling optical profiling system that collects profiles of spectral Lu, spectral Ed, chlorophyll fluorescence, backscatter, temperature, and salinity. In addition, a reference sensor on the ship measures spectral Ed above the water surface simultaneously. The system is calibrated by Satlantic and we use Satlantic software for processing. This software derives normalized water-leaving radiance ( $\mathrm{nLw})$ by extrapolating the profile data to the sea surface. The HyperPRO-derived nLw can be directly compared with atmospherically-corrected satellite data.

In addition to HyperPRO data, validation data routinely collected and available from the HOT and C-MORE programs include: chlorophyll and other pigments (fluorometric and HPLC) and primary productivity. All data are available from the HOT and C-MORE websites [7,8]. 
The main challenge with VIIRS data validation in this region are clouds. Hawaiian waters are frequently covered by scattered clouds. More often than not, clouds impede the satellite view of the region of interest. In addition, passing clouds influence the HyperPRO measurements, making it difficult to derive $\mathrm{nLw}$ accurately. For quality nLw data matchups, HyperPRO measurements must be made under clear skies.
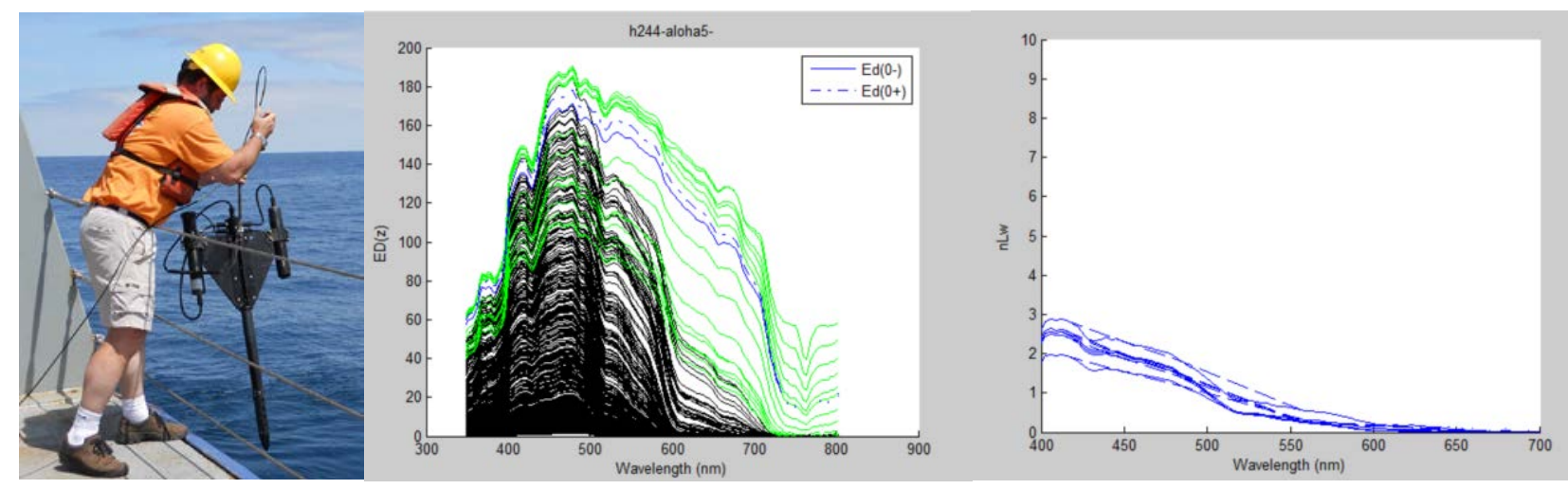

Fig. 2. HyperPRO data collection in Hawaii. Left: The HyperPRO just prior to deployment (photo by Angel White). Middle: Example spectra of downwelling irradiance at different depths on a clear day. Right: Normalized water-leaving radiance derived from the clear sky HyperPRO measurements (August 17, 2012).

\section{Validator Methods}

Data from the remote sensors VIIRS, MODIS, and MERIS for pre-specified 'golden regions' along the west coast are collected and added to a 'mySQL' data base (Fig. 3). The full orbit SDR for ocean color is about 8 GB. However by using the time stamps on the VIIRS granules we are only downloading and archiving the swaths surrounding our regions of interest (which encompasses all the US West Coast and Hawaii) which reduces our VIIRS data to 0.5 GB per pass. Data flow to and from OSU is shown in Figure 3.

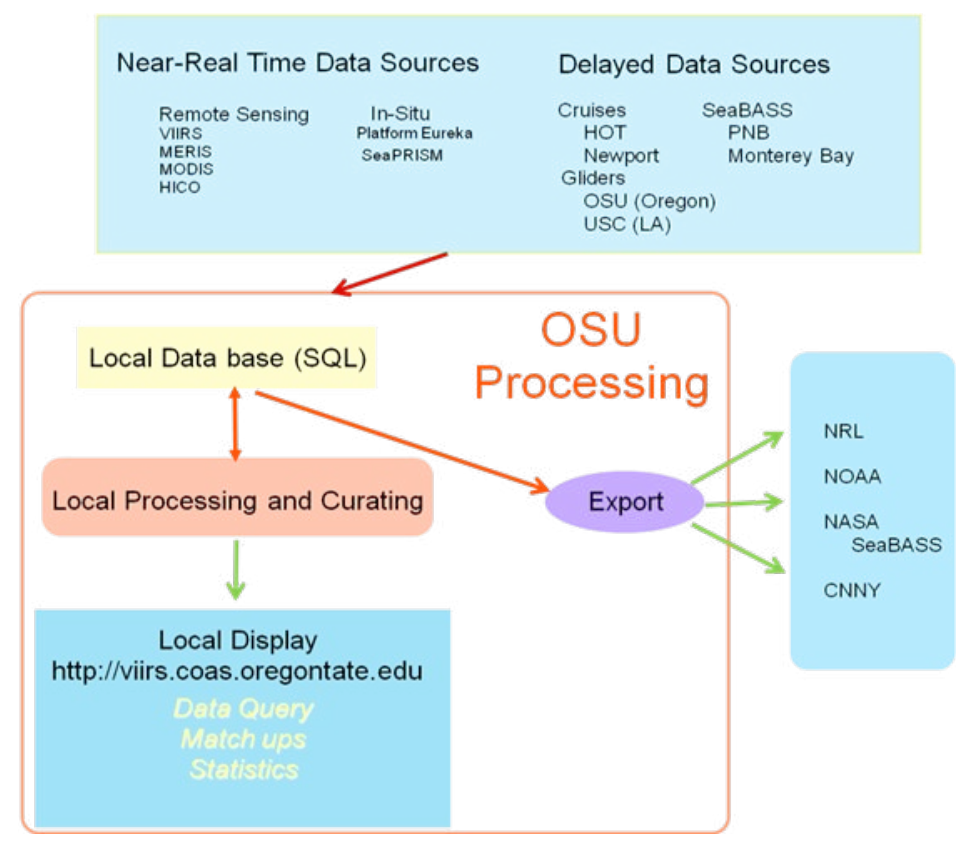

Fig. 3. Diagram showing flow of data sources and products to and from OSU. 
The data base is built in SQL (see the schema in Figure 4). We passed on our data base design to both NRL and CCNY and they both adopted/implemented it with some local changes.

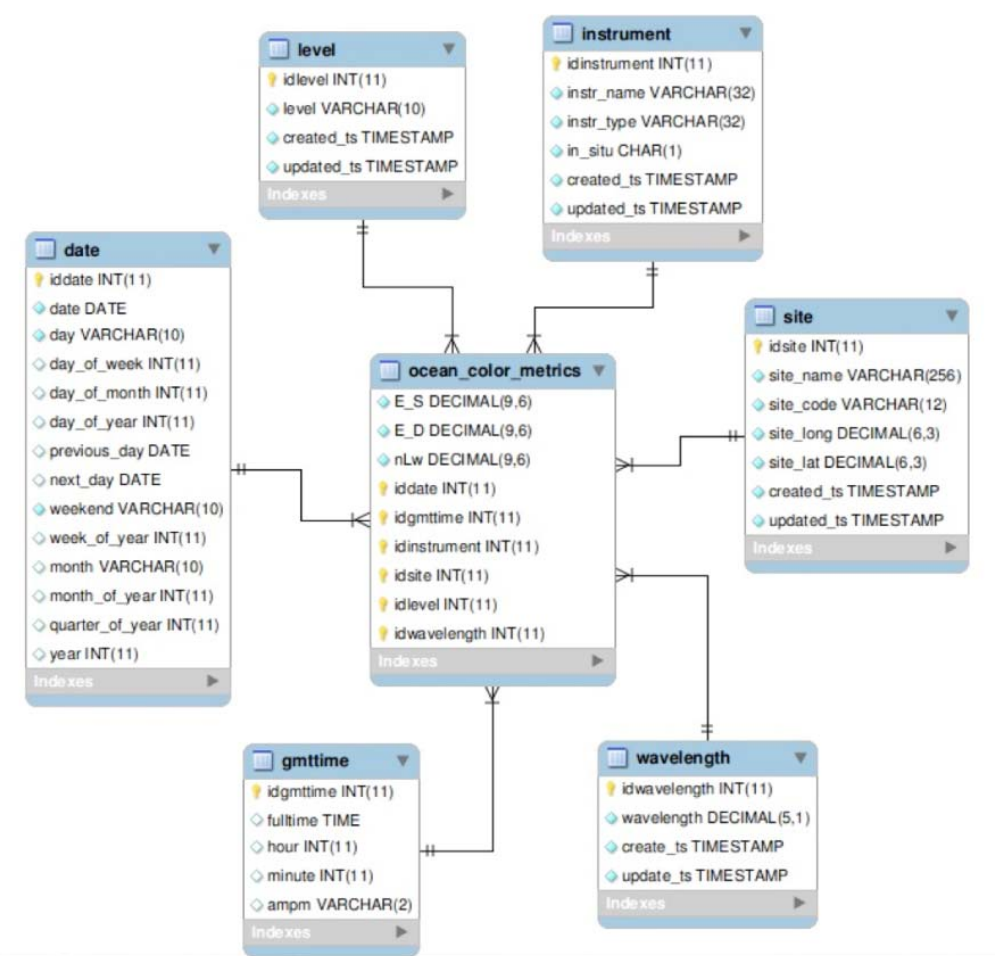

Fig. 4. Updated OSU Validator schema built in SQL for managing data in relational database management systems for the in situ and satellite data.

The MODIS and VIIRS image data subsets for the West Coast (Oregon, Platform Eureka, Santa Barbara channel PNB, and Monterey Bay) and Hawaii (HOT plus MOBY) Golden Regions archived at OSU with co-located in situ data and results of automated statistical analysis of the match ups will be available online at OSU (Figures 5-7). Statistical analysis includes those produced using the NRL-SSC and LISCO validator tools, namely means and standard deviations. In addition to daily, weekly, and seasonal statistics and correlations between in situ and remote sensing radiances, we will also produce (linear and nonlinear) regressions for calibration between remote sensing platforms (MERIS, VIIRS, MODIS, and HICO). These latter regressions will aid in multi-platform EDR continuity over time, as well as providing an additional check on sensor calibration. We are still working on codes for automating the match-ups, including the plotting and statistics. Right now we are generating these using Matlab routines. We are working on translating this to Python to automate it and make it more compatible with CCNY's routines. Data on the websites are access controlled; we are not 'broadcasting' live VIIRS data to the general public.

\section{EXAMPLE PRODUCTS}

For the HOT data which is from monthly cruises there are very few matchups due to the cloudy conditions and sun glint in this area. In the standard JPSS processing the flags for clouds and stray light around clouds are set very conservatively and many areas are masked that may have useful data which exacerbates this problem. However, when we have matched water leaving radiances from VIIRS the standard product and the HyperPRO the data show excellent agreement (Figure 5).

Comparisons of VIIRS and MODIS chlorophyll products for the Southern California Bight show generally good agreement (Figure 6). However, in the standard JPSS processing masking of areas with high reflectance due to high chlorophyll or other suspended matter limits the useful data along the coast. This is clearly seen in the comparison of the 

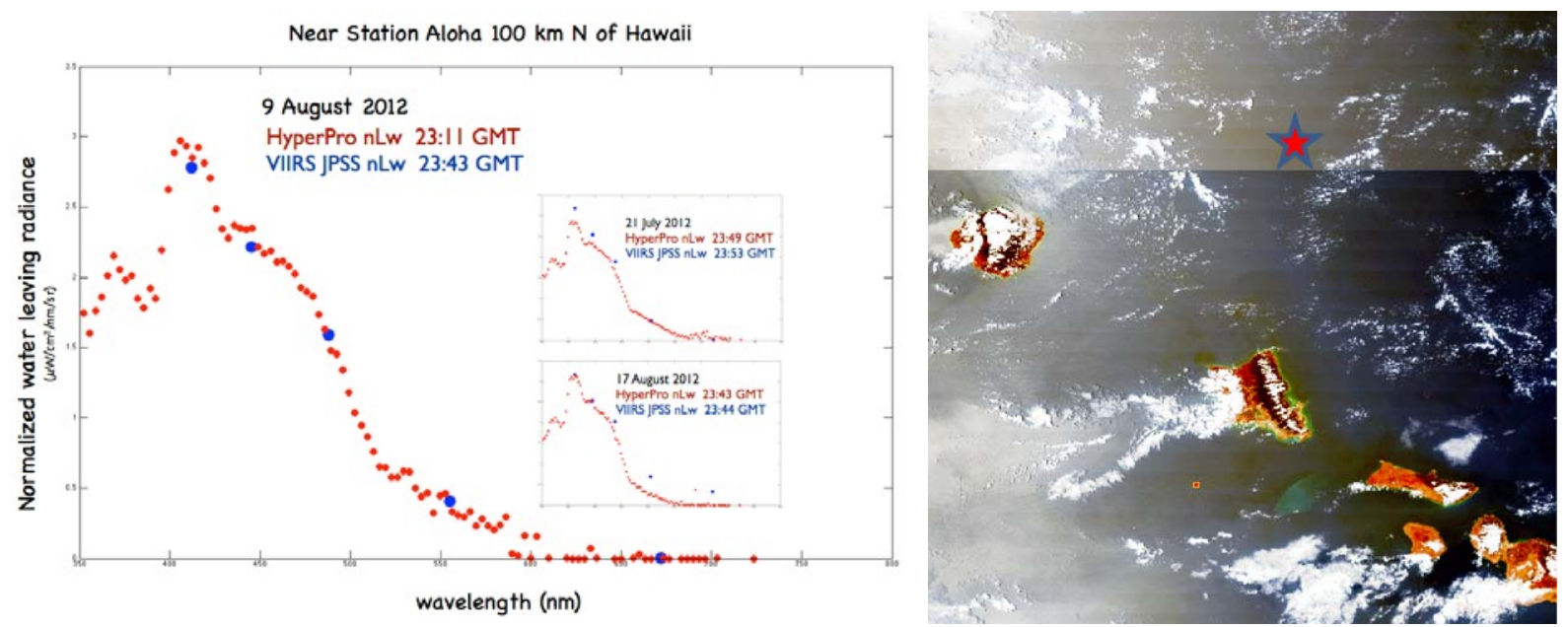

Figure 5. Left, Example spectral matches at Station ALOHA of VIIRS data with HyperPRO cruise data collected within one hour of each other. The VIIRS products shown here are computed with the JPSS processor and obtained from the NOAA CLASS archive. Right, VIIRS image over Hawaii from 17 August 2012 (23:43 GMT). The star marks Station ALOHA.

APS processed data and the JPSS standard product chlorophyll data. Time series analysis of the time series of chlorophyll at Platform Eureka (Figure 7) highlights this issue with VIIRS for the coastal ocean. As shown in Figure 7 there are many days when we have clear skies and obtain valid data from the SeaPRISM, but the VIIRS data is flagged and the chlorophyll value is set to 0 . We are supporting Menghua Wang and the team addressing this and other issues in an effort to obtain the best possible VIIRS ocean data products.

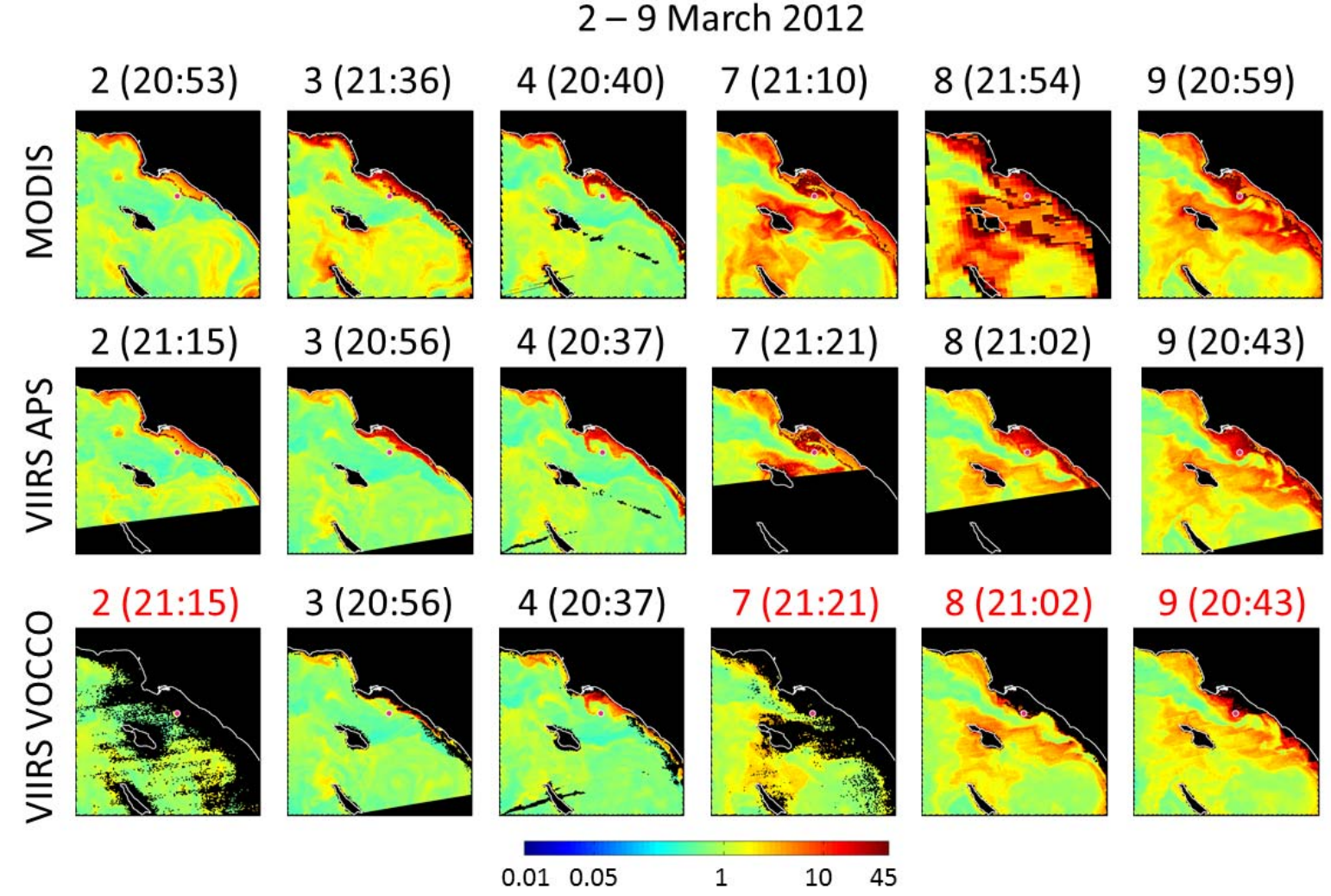

Fig. 6. A time series of satellite images from March 2012 over the Southern California Bight region. Top, Chlorophyll-a images from MODIS-AQUA, Middle, VIIRS APS chlorophyll, Bottom VOCCO VIIRS (standard algorithm). The red dot in the center of each image is the location of Platform Eureka. Flags for high reflectance cause a loss of VIIRS chlorophyll products (March 2,7,8,9). 
Moving forward we are analyzing the first full year of VIIRS data (March 2012-March 2013) at Platform Eureka. We are comparing the JPSS VIIRS standard products with and without flags with the SeaPRISM data and MODIS standard products. Further when new calibrations and particularly vicariously calibrated VIIRS data is available later this year we will revisit and update validation of the VIIRS products around Platform Eureka and HOT. These two sites (HOT in the low chlorophyll Central Pacific Gyre and Platform Eureka in typical coastal waters) represent $90 \%$ of the range of conditions for VIIRS ocean color data products and provide a good basis for the validation of that data.
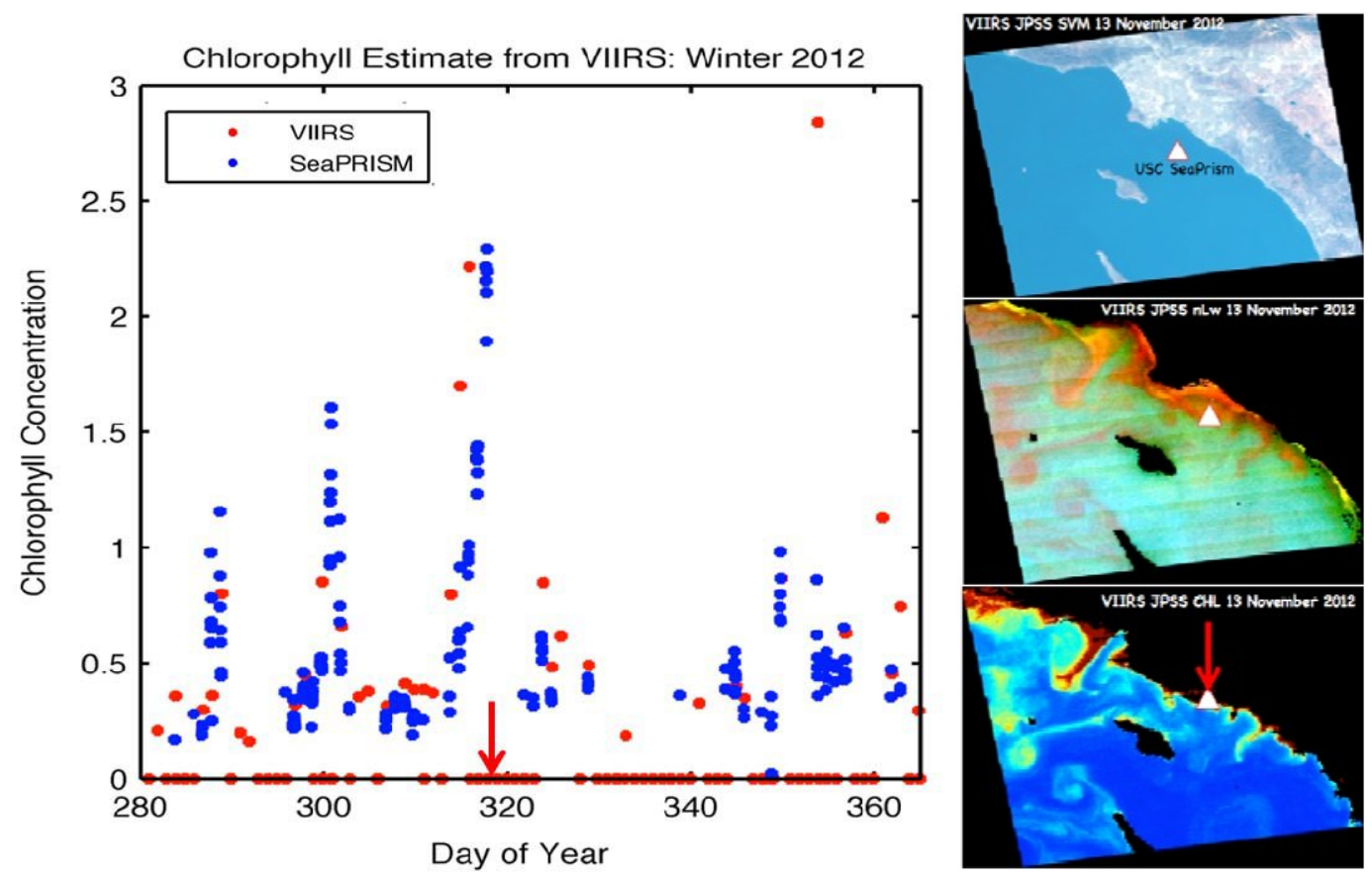

Fig. 7. Time series of chlorophyll-a data from VIIRS and Platform Eureka SeaPRISM showing periodic spikes and extensive loss of VIIRS data due to flags. Left, Chlorophyll-a values calculated from the Platform Eureka SeaPRISM water leaving radiances (blue dots) and the standard VIIRS product (red dots). Red arrow indicates the date of the image on right. Right, VIIRS images for day 318 showing clear conditions but the high chlorophyll value is flagged and set to 0. Triangle indicates the location of the Platform Eureka SeaPRISM.

\section{ACKNOWLEDGMENTS}

We thank NOAA JPSS for support for this effort. We also thank Adam Lawson and Paul Martinolich at the Naval Research Lab for assistance with product generation and instruction with their Advanced Processing System (APS), and the CCNY group, in particular Alex Gilerson and Carl Chinatomby for sharing their web interface for the validator.

\section{REFERENCES}

[1] Esaias, W., et al., 1998, “An Overview of MODIS Capabilities for Ocean Science Observations,” IEEE TGRS, Vol. 36(4): 1250-1265, (1998).

[2] STAR-JPSS Joint Polar Satellite System Algorithms and Products for VIIRS http://www.star.nesdis.noaa.gov/jpss/VIIRS.php

[3] Gordon, H. R., and M. Wang, "Retrieval of water-leaving radiance and aerosol optical thickness over the oceans with SeaWiFS: A preliminary algorithm," Appl. Opt. 33, 443-452 (1994).

[4] Wang, M. and Shi, W., "The NIR-SWIR combined atmospheric correction approach for MODIS ocean color data processing,” Optics Express 15 (24), 15722-15733 (2007). 
[5] Kim, H-J, Miller, A. J., McGowan, J., Carter, M. L., "Coastal phytoplankton blooms in the Southern California Bight," Progress in Oceanography 82, 137-147 (2009).

[6] Martinolich, P., et. al, “The automated processing system, Version 4.2.0,” Naval Research Laboratory, Stennis Space Center, MS: http://www7333.nrlssc.navy.mil/docs/aps_v4.2/html/user/aps/aps.xhtml, (2011).

[7] Zibordi, G. et. al., "AERONET-OC: A network for validation of ocean color primary products,” Journal of Atmospheric and Oceanic Technology 26, 1634-1651 (2009).

[8] Hawaii Ocean Time Series (HOT) website: http://hahana.soest.hawaii.edu/hot/

[9] Center for Microbial Oceanography: Research and Education (CMORE) website: http://cmore.soest.hawaii.edu/ 